\title{
HIV - RECENTES AVANÇOS NA PESQUISA DE FÁRMACOS
}

\author{
Wilson Cunico*, Claudia R. B. Gomes e Walcimar T. Vellasco Junior \\ Instituto de Tecnologia em Fármacos, Farmanguinhos, R. Sizenando Nabuco, 100, 21041-250 Rio de Janeiro - RJ, Brasil
}

Recebido em 13/11/07; aceito em 16/4/08; publicado na web em 16/10/08

\begin{abstract}
HIV - HIGHLIGHTS IN DRUG RESEARCH. The development of new antiretroviral drugs is a dynamic process that is continuously fueled by identification of new molecular targets and new compounds for know targets. The current available drugs can be classified into five categories: nucleoside analogues reverse transcriptase inhibitors, non-nucleoside reverse transcriptase inhibitors, protease inhibitors, integrase inhibitors and entry inhibitors (fusion inhibitors and CCR5 antagonist). In addition, the maturation inhibitors may be considered as potential target for chemotherapeutic intervention. This review presents some anti-HIV agents that have already gone through the advance development process for final approval for the treatment of AIDS.
\end{abstract}

Keywords: anti-HIV drugs; AIDS, new drugs.

\section{INTRODUÇÃO}

A síndrome de imunodeficiência adquirida (AIDS) é a doença infecciosa que mais mata no mundo. Desde que foi descoberta nos EUA, em 1981, a AIDS se espalhou rapidamente, sendo considerada uma epidemia mundial caracterizada por uma imunodeficiênica severa, infecções oportunísticas, neoplasia e um resultado fatal. ${ }^{1}$ Hoje, de acordo com dados da Organização Mundial de Saúde (OMS), 40 milhões de pessoas possuem a enfermidade. Do total de infectados, aproximadamente $95 \%$ vivem em países em desenvolvimento, sobretudo na África, onde $10 \%$ da população está contaminada. No Brasil, já foram notificados 600 mil casos. A AIDS não tem cura e já matou cerca de 20 milhões de pessoas desde o início da epidemia.

A doença é causada pelo vírus HIV (sigla em inglês para vírus da imunodeficiência humana), que compromete o funcionamento do sistema imunológico, impedindo-o de executar sua tarefa de proteger o organismo contra as agressões externas (por bactérias, outros vírus e parasitas) e contra células cancerígenas. Com o progressivo comprometimento do sistema imunológico, o corpo humano torna-se cada vez mais susceptível a doenças oportunistas. ${ }^{2}$

Somente no sangue, esperma, secreção vaginal e leite materno o vírus do HIV aparece em quantidade suficiente para causar a moléstia. Para haver a transmissão, o líquido contaminado de uma pessoa tem que penetrar no organismo de outra. Isso pode acontecer durante a relação sexual, ao se compartilhar seringas, agulhas e objetos cortantes infectados, na transfusão de sangue contaminado, no momento do parto e até durante a amamentação.

O HIV é um vírus e, como tal, é um germe microscópico que, devido a sua incapacidade de auto-reprodução (replicação), precisa infectar uma célula que servirá como hospedeira para a produção de novos vírus. Os vírus podem ser divididos em duas classes: aqueles cujo material genético consiste de DNA, e aqueles cujo material genético consiste de RNA, como o HIV. Os vírus de RNA são chamados retrovírus e o seu processo de reprodução é um pouco mais complexo que o dos vírus compostos de DNA. Fora da célula, o HIV é conhecido como vírion e é circundado por um envelope protetor, o qual circunda também uma determinada quantidade de proteínas virais e algum material genético, um "plano" contendo toda a informação necessária para a criação de novos vírus.

\footnotetext{
*e-mail: wjcunico@yahoo.com.br
}

\section{CICLO DE VIDA DO HIV}

O processo de entrada do vírus HIV começa com interações de alta afinidade da glicoproteína gp120 do vírus com a superfície dos receptores CD4 das células do hospedeiro como linfócitos T e macrófagos. Esta interação ocasiona mudanças conformacionais na gp120 que promove a participação de co-receptores, principalmente CCR5 ou CXCR4. Para a entrada do HIV na célula é necessária a ligação com estes co-receptores quimiocínicos para ativar mudanças conformacionais na membrana e posterior fusão. Estes primeiros eventos ativam a glicoproteína trimérica gp41 que media a fusão das membranas viral e celular. A fusão leva à injeção do capsídio do HIV à célula e posterior liberação do seu material genético e de enzimas necessárias para a replicação. Ocorre, então, a transcrição reversa do RNA genômico viral (formação do DNA a partir do RNA pela ação da enzima transcriptase reversa do HIV), que culmina na formação de uma dupla hélice de DNA viral. O DNA é transportado para dentro do núcleo celular, onde sofre clivagens específicas e é integrado ao DNA da célula do hospedeiro pela ação da enzima integrase. A ativação da célula hospedeira resulta na transcrição do DNA em RNA mensageiro, que é traduzido em proteínas virais. A enzima protease do HIV é necessária neste passo para clivar a poliproteína viral precursora em proteínas individuais maduras. O RNA e as proteínas virais agrupam-se na superfície celular como um novo vírion e são liberados para infectar outra célula (Figura 1). ${ }^{2}$

\section{INIBIDORES DE FUSÃO}

Freqüentemente, os vírus tendem a infectar determinadas células nos hospedeiros humanos, animais e vegetais. O vírus HIV infecta, principalmente, as células contendo a molécula CD4 em suas superfícies. A CD4 é encontrada em células imunológicas, principalmente nos linfócitos T-auxiliares que são responsáveis pelo funcionamento do sistema imunológico e, também, nos macrófagos, células que percorrem o organismo combatendo bactérias e outros germes. Para penetrar nas células, o HIV une-se ao receptor da CD4 através da glicoproteína gp120 que é encontrada em sua superfície. Uma vez unido à CD4, o HIV ativa outras proteínas na superfície da célula humana, conhecidas como co-receptores CCR5 e CXCR4, completando assim a fusão. ${ }^{3}$

São chamados inibidores de fusão os medicamentos anti-HIV que atacam o vírus nesse estágio do seu ciclo de vida. Apenas o composto T-20 (1, enfuvirtide, Fuzeon $\left.{ }^{\circledR}\right)$ foi aprovado pelo FDA para uso clí- 


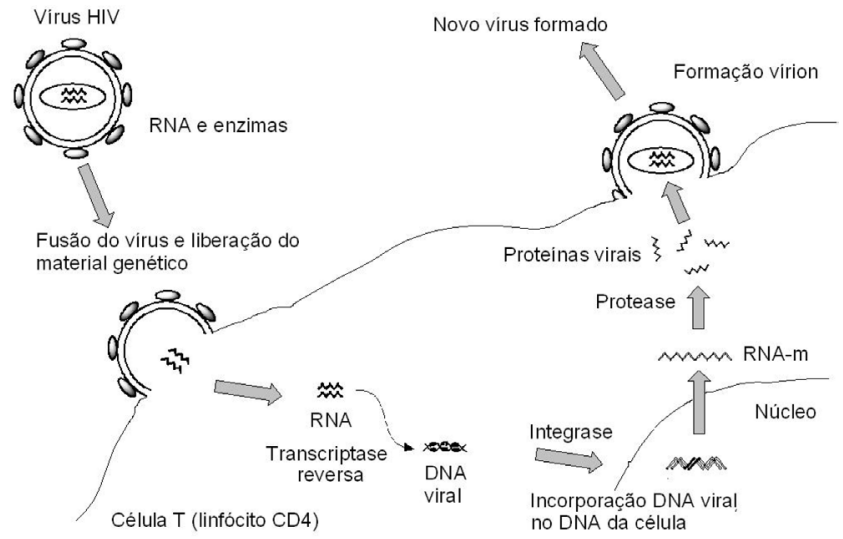

Figura 1. Ciclo de vida resumido da replicação viral do HIV

nico. O T-20 é um polipeptídeo constituído de 36 aminoácidos que interage com a gp41 impedindo a fusão do vírus com a membrana da célula (Figura 2). ${ }^{4}$

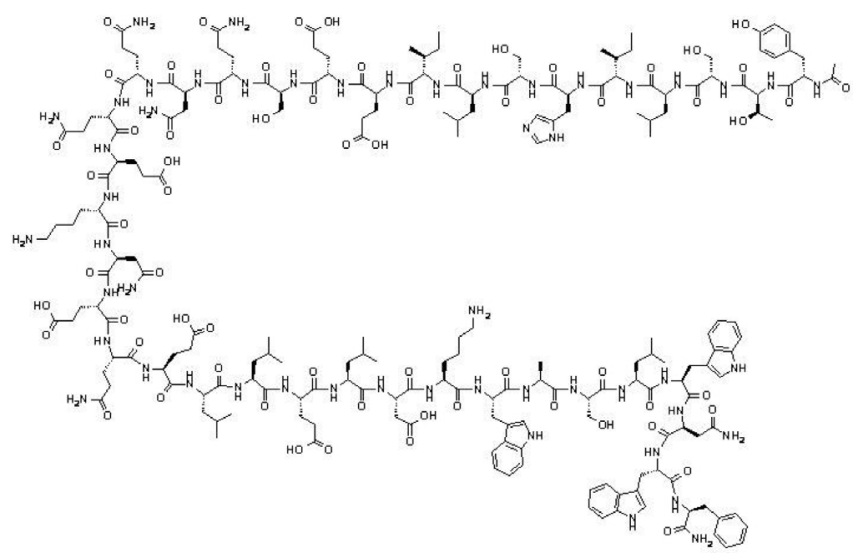

Figura 2. Estrutura do T-20 (1)

Dentre os novos candidatos a inibidores de fusão, destacam-se o maraviroc $^{5}$ (2, Pfizer), o vicriviroc ${ }^{6}$ (3, Schering-Plough) e o aplaviroc ${ }^{7}$ (4, GlaxoSmithKline) (Figura 3). Estas moléculas diferem do modo de ação do T-20 por serem antagonistas dos co-receptores CCR5 e CXCR4. Deste modo, ocorre o acoplamento no receptor CD4, porém a glicoproteina gp41 do vírus não interage com os co-receptores, não havendo a penetração do vírus na célula. $\mathrm{O}$ aplaviroc (4) recentemente teve a fase II descontinuada, devido apresentar sérios problemas
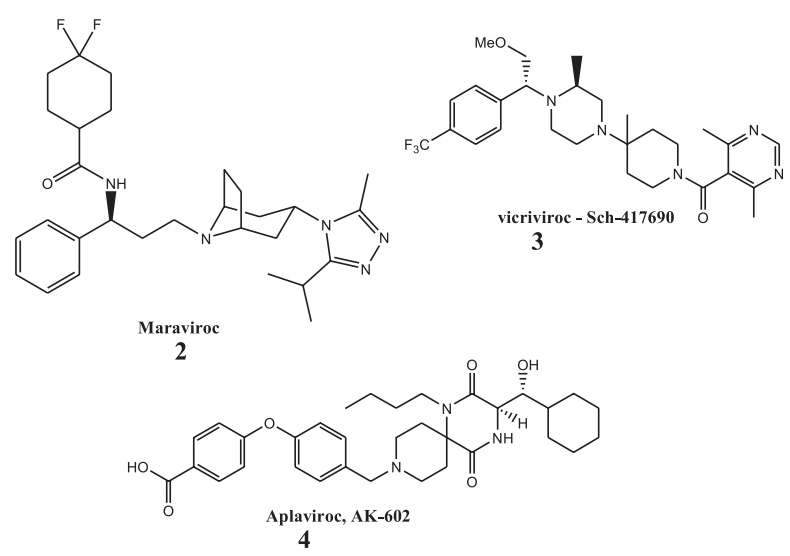

Figura 3. Antagonistas do co-receptor CCR5 hepáticos nos pacientes nesta e em fases anteriores. $\mathrm{O}$ vicriviroc (3), por sua vez, não apresentou efeitos colaterais significantes, porém quando administrado juntamente com o Combivir ${ }^{\circledR}$ (lamivudina + AZT) apresentou redução da carga viral inferior comparado à redução da carga viral no tratamento do efavirenz mais o Combivir ${ }^{\circledR}$. Novas experiências estão sendo realizadas com o vicriviroc (3) que se encontra em fase clínica III. O maraviroc (2), Selzentry ${ }^{\circledR}$, recentemente (agosto de 2007) foi aprovado pelo FDA para ser usado em combinação com outros antiretrovirais no tratamento da AIDS.

Atualmente, o PRO 140 (Progenics), anticorpo monoclonal produzido a partir do co-receptor CCR5 do HIV, e o INCB 9471 (Incyte Corpotarion), antagonista não competitivo do CCR5, estão em estudo de fase clínica II. O TNX 355 (Tanox) é um anticorpo monoclonal produzido do receptor CD4, administrado por via intravenosa que também está em fase clínica II. ${ }^{8}$

O protótipo para antagonistas do CXCR4 foi o AMD3100 (5) que é específico para o co-receptor CXCR4 do HIV não interagindo com outros receptores CXCR ou CCR (Figura 4). Durante a fase clínica I foi descoberto um aumento de glóbulos brancos nos voluntários. O AMD3100 (5) teve seus estudos contra o HIV, suspensos e agora se encontra em fase clínica II, para mobilização de células troncos e transplante em pacientes com mieloma múltiplo e linfoma nãoHodgkin. O AMD070 é um derivado biodisponível oral do AMD3100 (5), porém sua estrutura ainda não está disponível. Esta molécula está em fase clínica II como antagonista do co-receptor CXCR4. ${ }^{9}$

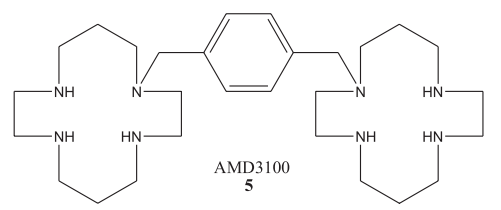

Figura 4. Protótipo para antagonistas do co-receptor CXCR4

\section{INIBIDORES DA TRANSCRIÇÃO REVERSA}

Uma vez ocorrida a fusão, a parte interior do vírus, composta pelo RNA e algumas enzimas importantes, é absorvida pela célula humana. Em seguida, a enzima viral denominada transcriptase reversa recodifica o material genético do HIV, convertendo-o de RNA para DNA.

Três classes de medicamentos anti-HIV atacam o vírus nesse estágio: os análogos de nucleosídeo (AZT/zidovudina, ddI/didanosina, 3TC/lamivudina, d4T/stavudina, ddC/zalcitabina, ABC/abacavir e FTC/emtricitabina); os análogos de nucleotídeo (tenofovir, adefovir) e, os inibidores não-nucleosídeos da transcriptase reversa (efavirenz, neviparina, delavirdina).

Os inibidores nucleosídeos necessitam ser transformados em seus metabólitos para inibir a transcriptase reversa do HIV e, conseqüentemente, impedir a formação do DNA viral. Esta transformação ocorre por ação de enzimas que trifosforilam estes análogos.

Dentre os análogos de nucleosídeo que estão em desenvolvimento, o racivir [6, ( \pm - $\beta$-2',3'-dideoxi-3'-tia-5-fluorcitosina ou \pm FTC] da Pharmasset possui um ótimo perfil de segurança e além da atividade antiHIV, apresenta atividade contra o vírus da hepatite B (Figura 5). O racivir (6) consiste na mistura de 1:1 do emtricitabina (-FTC, Emtriva ${ }^{\circledR}$ ) e seu enantiômero (+FTC) sendo mais ativo que os enantiômeros puros..$^{10}$

O AVX $457^{11}$ (7, apricitabina) está na fase II e possui atividade contra vírus HIV selvagem (que não sofreu mutações) e alguns mutantes, inclusive vírus resistentes ao AZT e lamivudina. Possui boa propriedade farmacocinética sendo facilmente absorvido pelo organismo, porém tem sua concentração reduzida quando administrado juntamente com 3TC, sugerindo que este composto não deve ser usado clinicamente com análogos da citidina. ${ }^{12}$ 
<smiles>Nc1nc(=O)n(C2CSC(CO)O2)cc1F</smiles><smiles>Nc1ccn(C2COC3OCC32)c(=O)n1</smiles><smiles>Nc1nc(=O)n(C2OC3C=CC2C3)cc1F</smiles><smiles>Cc1cn(C2CC(F)C3CC2O3)c(=O)[nH]c1=O</smiles><smiles>Nc1nc(=O)n(C2C3COC(O3)C2O)cc1F</smiles>

Figura 5. Inibidores de análogos de nucleosídeos do HIV em fase clínica avançada

O reverset ${ }^{13}$ (8, dexelvucitabina) teve sua fase clínica II descontinuada em abril de 2006, devido à presença de $40 \%$ de enzimas lipases no sangue causando hiperamilasemia, proveniente de uma possível lesão no pâncreas. O reverset (8) era um dos compostos mais promissores desta classe, pois possuía boa atividade contra vírus mutantes. ${ }^{14}$ Outra molécula que teve sua fase clínica descontinuada foi a alovudina (9) em 2005.

A elvucitabina (10) apresenta atividade contra vírus resistentes à zidovudina e lamivudina e também é ativa contra o vírus da hepatite tipo $\mathrm{B}$, porém a dose utilizada deve ser diminuída devido a problemas na medula óssea em alguns pacientes. Doses menores estão sendo testadas para determinar se esta molécula será útil no combate ao HIV. ${ }^{12}$

O amdoxivir (11) é o pró-farmaco da dioxolano guanosina (DXG, 12) e além da atividade anti-HIV possui ação contra o vírus da hepatite B. ${ }^{15}$ Intracelularmente, o amdoxivir é deaminado seletivamente pela enzima adenosina deaminase resultando no DXG (12) (Figura 6). ${ }^{16}$ Atualmente o amdoxivir (11) está em fase clínica II
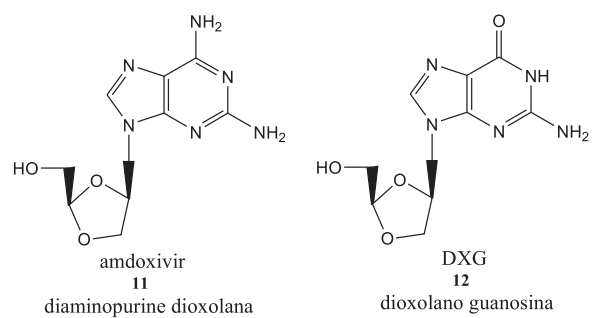

Figura 6. DXG (12) e seu pró-farmaco amdoxivir (11)

\section{INIBIDORES NUCLEOTÍDEOS DA TRANSCRIPTASE REVERSA}

A primeira fosforilação é a etapa crucial para a formação dos metabólitos ativos dos inibidores nucleosídeos. Muitas moléculas não apresentam atividade devido à dificuldade de serem monofosforiladas. Com o intuito de contornar este problema, vários análogos nucleotídeos, como adefovir e tenofovir, foram sintetizados. Estes fármacos já possuem um grupo fosfato em sua estrutura e necessitam de apenas duas fosforilações para impedir a transcrição do RNA em DNA e, portanto, impedir a replicação viral.

Os análogos de nucleotídeos em uso clínico são o adefovir (PMEA,
13) e o tenofovir (PMPA, 14) (Figura 7). Ambos compostos são pouco solúveis em água e possuem baixa biodisponibilidade quando administrados oralmente. Para contornar este problema, diversos ésteres foram sintetizados. O éster é metabolizado in vivo produzindo o princípio ativo, aumentando a biodisponibilidade do fármaco. No caso para o PMEA (13), o pró-farmaco que apresentou melhores resultados foi o bis(pivaloiloximetil)PMEA (15), ${ }^{17}$ porém teve seus estudos abandonados devido à alta toxicidade. Este fármaco, entretanto, foi aprovado pela FDA, órgão americano responsável pelo liberação de fármacos no mercado, para o tratamento de hepatite B, pois tem significante redução viral em uma dose não tóxica (10 mg dia). ${ }^{18}$
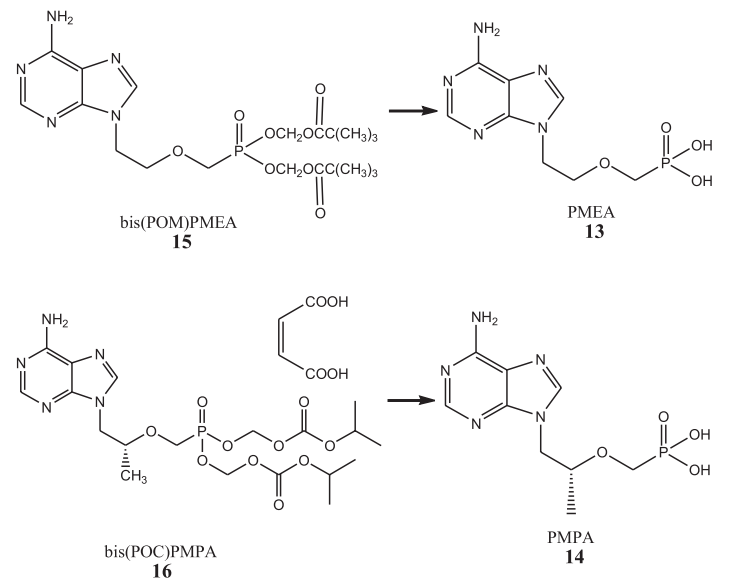

Figura 7. Inibidores análogos de nucleotídeos da transcriptase reversa do HIV

O pró-fármaco que apresentou melhores resultados para o PMPA (14) foi o bis(isopropiloximetilcarbonil)PMPA (16) que tem seu metabolismo representado na Figura $8 .{ }^{19} \mathrm{~A}$ hidrólise do bisc(POC) PMPA (16), promovida pela enzima esterase, gera estequiometricamente duas moléculas de isopropanol, duas de dióxido de carbono, duas de formaldeído e uma molécula de PMPA (14).

A enzima AMP kinase é a responsável pelas duas fosforilações do tenofovir e do adefovir. O PMPApp (tenofovir difosforilado) possui o mínimo de interferência na síntese do DNA humano, o que explica sua baixa toxicidade e segurança no tratamento do HIV. Outro fator importante do tenofovir são suas múltiplas conformações quando complexado na cadeia de DNA do vírus. Diferentemente dos agentes anti-HIV análogos de nucleosídeo cíclicos que são estáticos e rígidos (3TC, AZT), a mobilidade do tenofovir impede o desenvolvimento da resistência do vírus ao fármaco. ${ }^{20} \mathrm{O}$ tenofovir também está sendo estudado como microbicida, ou seja, usado na forma de gel como agente de prevenção contra o HIV.

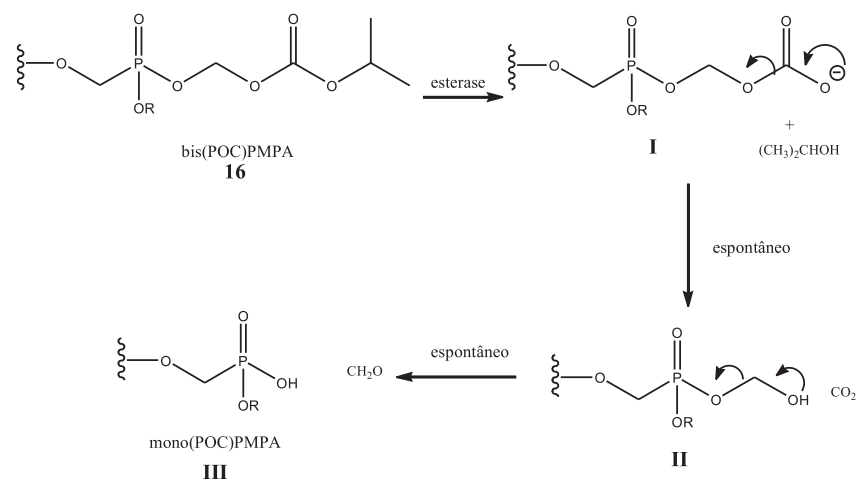

Figura 8. Metabolismo in vivo do bis(POC)PMPA 16 


\section{INIBIDORES NÃO-NUCLEOSÍDEOS DA TRANSCRIPTASE REVERSA DO HIV}

Os inibidores não-nucleosídeos da transcritase reversa do HIV (NNTRs) são inibidores não competitivos que se ligam a um sítio alostérico da enzima. Como resultado desta interação, o sítio ativo responsável pela formação da dupla hélice de DNA tem sua mobilidade e flexibilidade restritas, que acarretam em uma drástica redução da eficiência da enzima. ${ }^{21}$

Apenas três fármacos foram aprovados pelo FDA, nevirapina (Viramune $^{\circledR}$ ), delavirdina $\left(\right.$ Rescriptor $^{\circledR}$ ) e efavirenz (Sustiva ${ }^{\circledR}$ ). Devido ao potencial destes fármacos, são amplamentes usados como componentes do HAART. A nevirapina é, inclusive um dos poucos fármacos utilizados para prevenir a transmissão do HIV de mãe para filho.

Mais de 30 classes de moléculas com diferentes estruturas foram identificadas como inibidores da transcriptase reversa do HIV. Infelizmente a grande maioria destas moléculas tem suas fases clínicas descontinuadas por diversos motivos, como toxidade; propriedade farmacocinética ruim; baixa eficácia in vivo; potência insuficiente contra vírus mutantes. ${ }^{22}$

A geração de NNTRs mais promissora é a classe das diarilpirimidinas (DAPY - diarylpyrimidines). A descoberta dos DAPY é resultado de 20 anos de pesquisa, iniciada em 1987 com a molécula TIBO, uma das primeiras moléculas não-nucleosídicas inibidoras da transcriptase reversa (Figura 9). ${ }^{23}$ O TIBO (17), assim como a nevirapina e o $\alpha$-APA (18), liga-se ao sítio em uma conformação "tipo-borboleta". Novas moléculas foram sintetizadas baseadas no $\alpha$-APA (18), sendo que o ITU (19) (imidotiouréia) mostrou ser uma classe promissora. A molécula de ITU (19) por ser mais flexível que o $\alpha$-APA (18), liga-se ao sítio com uma conformação ferradura "tipo U”. Os derivados desta série apresentaram potência superior contra os vírus mutantes resistentes ao TIBO (17) e à nevirapina, que possuem ligação "tipo-borboleta", porém a instabilidade da imidotiouréia aparentemente não é ideal para um fármaco oral. O próximo passo foi a obtenção das moléculas DATA
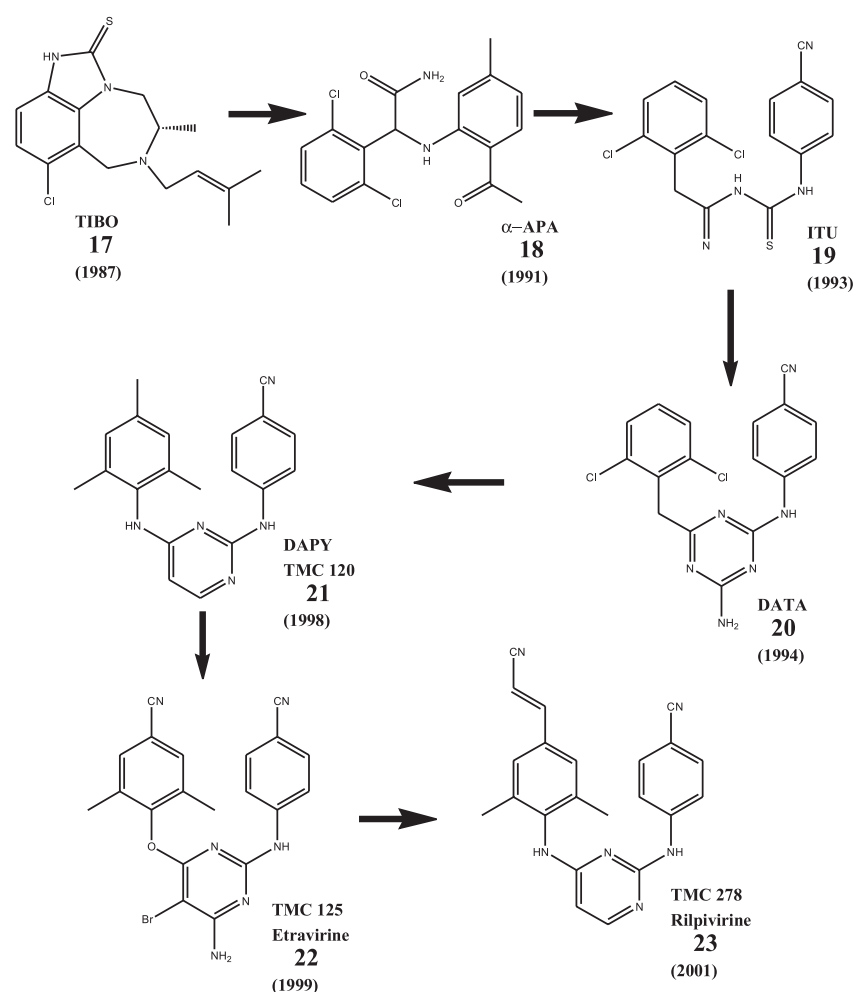

Figura 9. Geração promissora de inibidores não-nucleosídeos da transcriptase reversa do HIV
(20) (diariltriazinas). Nestas moléculas, a tiouréia presente no ITU (19) foi substituída pelo anel triazina, mantendo a mesma conformação tipo ferradura. $\mathrm{O}$ anel reduziu algumas torções irrelevantes na parte central, preservando a flexibilidade nas "asas". A restrição destas indesejadas rotações é esperada que seja entropicamente favorável, corroborando a atividade superior dos derivados DATA (20) em comparação com seus predecessores.

Estudo de modelagem molecular usando estruturas cristalográficas disponíveis de complexos ligante-enzima sugeriu a substituição do anel triazina pelo anel pirimidina, levando à formação da classe DAPY, onde o TMC120 (21) (dapivirine) foi o protótipo. O dapivirine (21) teve sua fase clínica descontinuada para o tratamento do HIV, porém está em andamento seu uso como agente microbicida, prevenindo a transmissão vaginal do HIV (Fase II). ${ }^{24} \mathrm{O}$ etravirine (22) (TMC125) teve seus estudos clínicos finalizados em agosto de 2007 e em janeiro de 2008 foi aprovado pelo FDA para o combate ao HIV sob o nome comercial de Intelence. ${ }^{25}$ Outra molécula desta classe, o rilpivirine (23) (TMC 278), apresenta atividade superior contra os vírus selvagens e mutantes, comparada aos fármacos aprovados pelo FDA e, inclusive, superior ao etravirine. Além disso, o TMC 278 (23) possui uma síntese simples ${ }^{26}$ e encontra-se em estudos de fase clínica III.

O grande trunfo da nova geração de inibidores não-nucleosídeos da transcriptase reversa do HIV é a flexibilidade das moléculas DAPY. Estudo de modelagem molecular dos complexos entre a enzima e os inibidores mostra que existem diversos modos de ligação entre os fármacos e a enzima. O DAPY possui conformações que permitem o reposicionamento e a reorientação da molécula no sítio e, consequentemente, possui atividade contra vários vírus mutantes que são resistentes aos fármacos nevirapina e efavirenz..$^{23}$

Entre outras classes de moléculas destacam-se três novas que estão em fase clínica II, o MIV-15027 (24) (Medivir Pharmaceutical), o BILR 355BS (25) (Boehringer-Ingelheim) e o (+)-calanolida A (26) (Sarawak Medichem Pharmaceuticals) (Figura 10). A calanolida (26) é um produto natural extraído da planta Callophylum, encontrada principalmente nas florestas da ilha de Borneo (Malásia, Indonésia e Brunei).

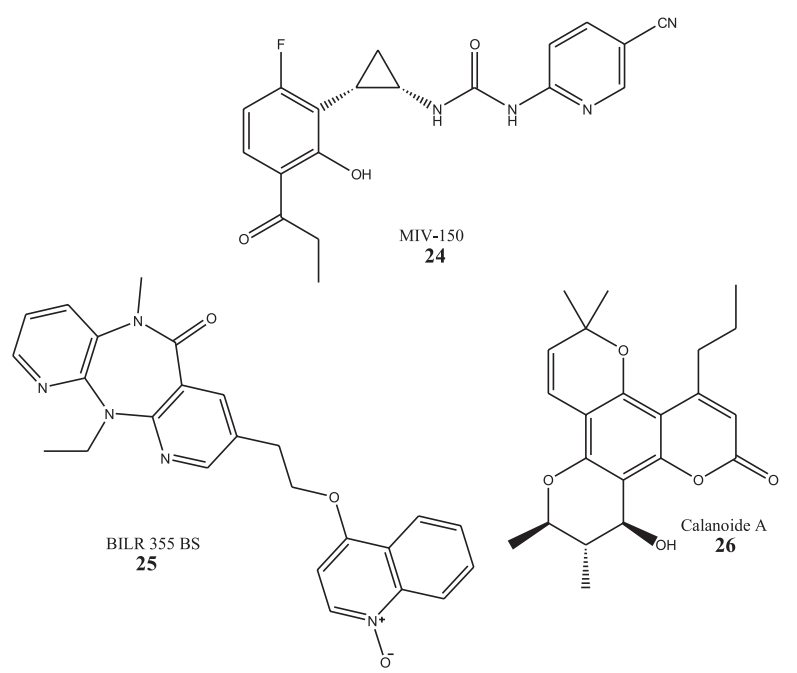

Figura 10. Moléculas análogas de não-nucleosídeos da transcriptase reversa do HIV em fase clínica II

\section{INIBIDORES DA PROTEASE}

A enzima viral chamada protease é responsável pelo processamento das poliproteínas gag e gag-pol, levando à formação das proteínas estruturais e funcionais responsáveis pela formação da estrutura 
de uma nova partícula do vírus. A protease do HIV pertence à família das aspartil proteases, ou seja, possui dois grupos $\beta$-carboxi aspartil no sítio ativo. Estes grupos (Asp 25 e Asp 25') são responsáveis por catalisar a hidrólise das ligações peptídicas (Figura 11). ${ }^{28}$ Conforme o mecanismo, um resíduo aspartil auxilia na adição de uma molécula de água à carbonila da amida do substrato, formando um intermediário tetraédrico que possui grande afinidade pelo sítio catalítico. Após a formação deste intermediário, ocorre a quebra da ligação C-N com a formação de um ácido carboxílico e de uma amina primária. Substâncias químicas que mimetizem este intermediário tetraédrico impedem a hidrólise do substrato e, conseqüentemente, o ciclo do vírus HIV é interrompido. ${ }^{29}$

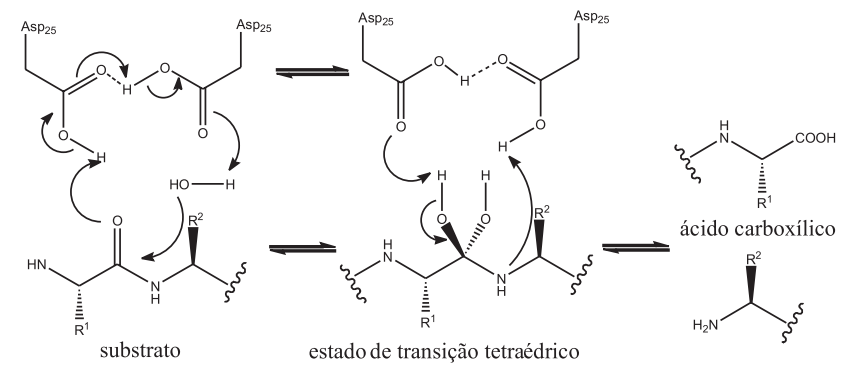

amina

Figura 11. Mecanismo de hidrólise do substrato viral na enzima protease do HIV

Os inibidores da protease do HIV interferem no último estágio da replicação viral, prevenindo a formação de novos vírus. ${ }^{28} \mathrm{~A}$ Figura 12 mostra a estrutura geral de moléculas que foram estudadas como peptídeos miméticos e, portanto, inibidores da enzima protease do HIV. A maioria dos fármacos licenciados pelo FDA possuem em sua estrutura uma ligação hidroxietileno ou uma ligação hidroxietilamina. São eles: saquinavir; ritonavir; indinavir; nelfinavir; amprenavir; fosamprenavir, lopinavir; atazanavir. ${ }^{30}$

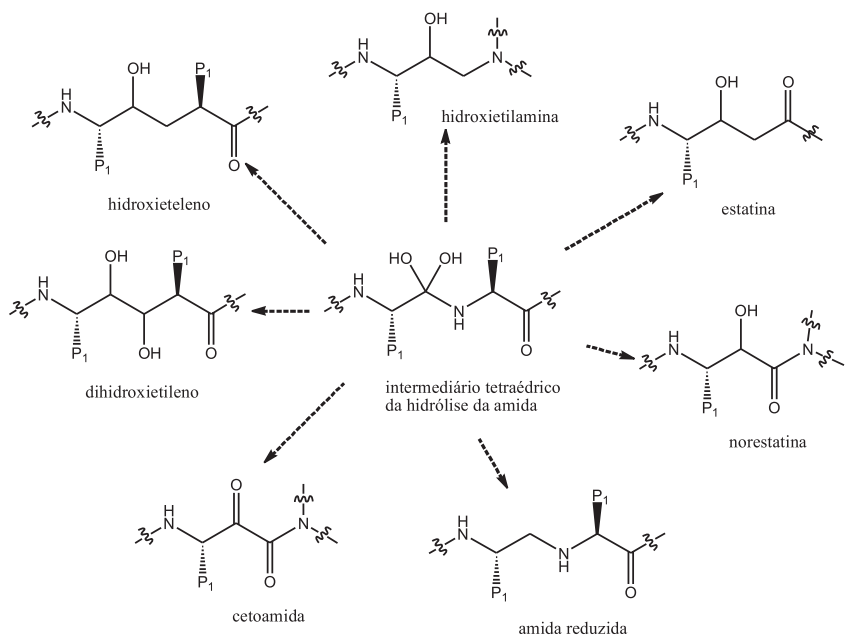

Figura 12. Estrutura geral de moléculas desenvolvidas como inibidores da protease do HIV

O tipranavir (27) (Aptivus $^{\circledR}$ ) foi aprovado em 2005 para o uso clínico e é o único fármaco que estruturalmente não é peptideomimético (Figura 13) ${ }^{31}$ Devido a isso, o tipranavir possui boa atividade contra a maioria dos vírus mutantes resistentes aos demais fármacos desta classe. O tipranavir (27) pode ser administrado em pacientes que apresentaram falha no tratamento com os demais inibidores da protease..$^{32}$

O último fármaco desta classe a ser aprovado pelo FDA foi o da-

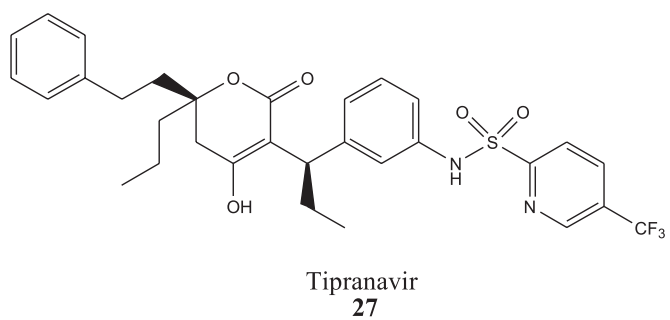

Figura 13. Estrutura do tipranavir (27)<smiles>CC(C)CN(C[C@H](O)[C@H](CPc1ccccc1)NC(=O)O[C@H]1CO[C@@H]2OCC[C@H]21)S(=O)(=O)c1ccc(N)cc1</smiles>

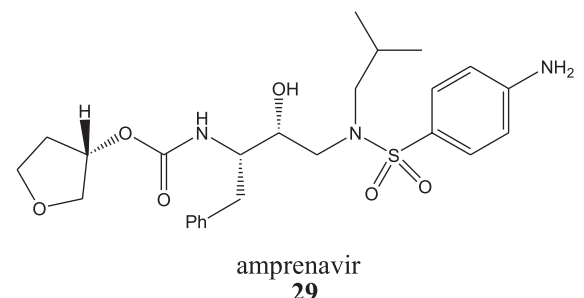

Figura 14. Estruturas do darunavir (28) e seu protótipo amprenavir (29)

runavir (28) (TMC-114, Prezista $^{\circledR}$ ) em junho de 2006 (Figura 14). O planejamento estrutural do darunavir (28) foi realizado com o objetivo de aumentar o número de interações favoráveis com os átomos do sítio ativo da protease, tendo como protótipo o amprenavir (29). O objetivo foi atingido através da inclusão do grupo bis-tetra-hidrofurano. ${ }^{33,34}$

Estudo recente mostra que o TMC 114 (28) possui dois sítios de ligação na enzima protease: um no próprio sítio ativo e outro em um dos flaps móveis do dímero. O TMC 114 (28) liga-se simultaneamente a estes sítios, devido à formação de enantiômeros pela inversão do nitrogênio do grupo sulfonamida (Figura 15). Entretanto, o flap acomoda melhor o diastereoisômero com o nitrogênio $S$-enantiômero. A existência deste segundo sítio de ligação sugere um mecanismo para a grande efetividade do darunavir contra os vírus mutantes que são resistentes aos demais fármacos da classe. ${ }^{35}$ Estão em andamento estudos com

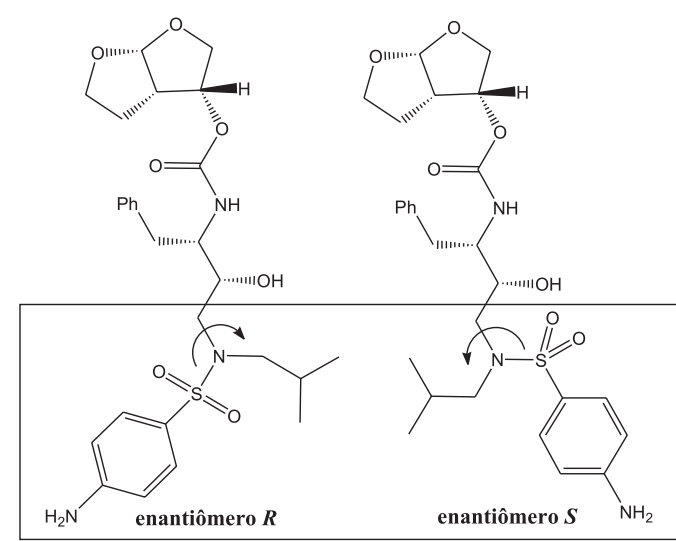

Figura 15. Enantiômeros pela rotação no nitrogênio da sulfonamida do TMC 114 (28) 
intuito de identificar e desenvolver moléculas que possam inibir sítios alostérios da protease, provocando uma mudança na flexibilidade da enzima e, conseqüentemente, impedindo a ligação com o substrato. ${ }^{36}$

A molécula desta classe de fármacos que estava em fase clínica mais avançada era o brecanavir (30) (Figura 16), ${ }^{37}$ porém seu estudo foi descontinuado em dezembro de 2006, devido a problemas na dosagem da formulação.

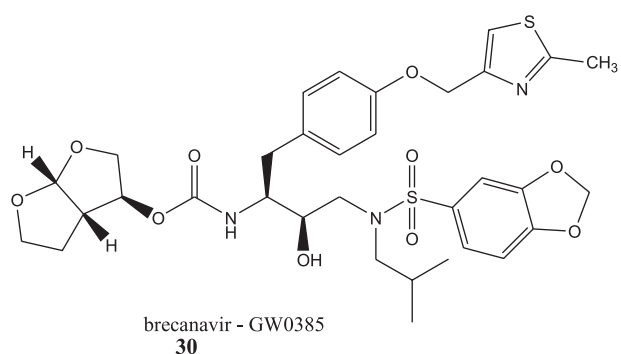

Figura 16. Estrutura do brecanavir (30)

\section{INIBIDORES DA INTEGRASE}

A enzima integrase do HIV é essencial para a replicação viral, sendo responsável por inserir o DNA próviral no cromossomo do hospedeiro e por catalisar a incorporação deste DNA próviral ao genoma da célula infectada. Esta enzima é um importante alvo para a pesquisa e desenvolvimento de novos antiretrovirais, possuindo a vantagem de não apresentar qualquer homólogo celular, possibilitando o desenvolvimento de fármacos com menor índice de efeitos colaterais. ${ }^{38}$

Desde o descobrimento da enzima integrase como um possível alvo terapêutico, várias substâncias testadas apresentaram atividade inibitória da enzima integrase in vitro, ${ }^{39}$ porém poucos inibidores passaram para a fase de testes clínicos, ${ }^{40}$ destacando-se o MK-0518 (Raltegravir 31, Isentress ${ }^{\circledR}$ ), da Merck, que foi o primeiro inibidor desta classe aprovado pelo FDA para o tratamento de HIV/AIDS, em outubro de $2007^{41}$ (Figura 17); o S-1360 (32), da ShianogiGlaxo Smith Kline, e o L-870,810 (33), também da Merck Research Lab., tiveram seus testes descontinuados devido a problemas de farmacocinética; o GS-9137 (34, JKT-303, Eltegravir), ${ }^{42}$ desenvolvido quimicamente pela empresa Japan Tobacco, foi licenciado em março de 2005 pela multinacional Gilead, encontrando-se em fase II dos testes clínicos, assim como o GSK-364735 (S-364735, 35) da Shianogi-Glaxo Smith Kline.

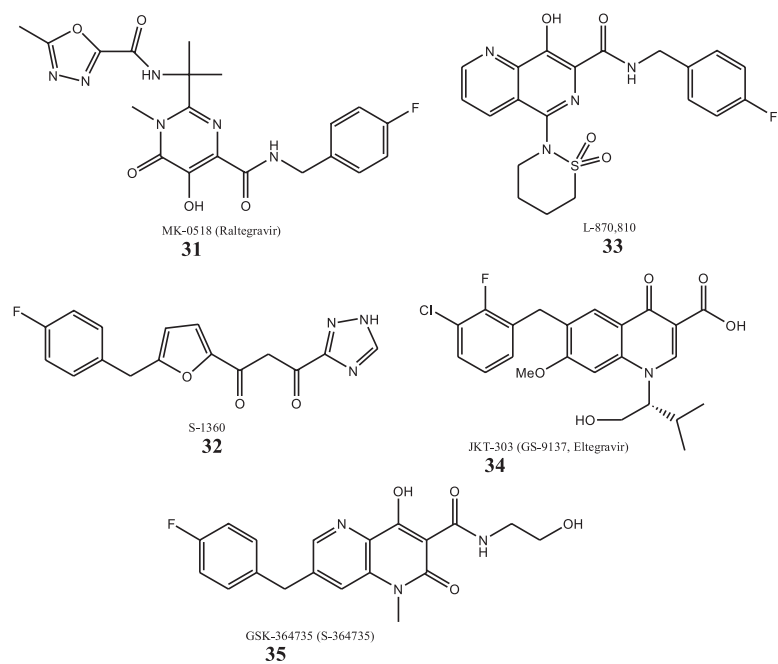

Figura 17. Inibidores da integrase em desenvolvimento clínico

\section{INIBIDORES DA MATURAÇÃO}

O composto PA-457 (36), que recentemente recebeu o nome de bevirimat, é o único inibidor de maturação em fase clínica. Esta molécula não atua em enzima ou em receptor e sim no último estágio do processamento do gap, interrompendo a conversão do capsídeo viral precursor (p25) no capsídeo maturado (p24). Devido a estas partículas virais possuirem este defeito, o vírus que sai da célula não é infeccioso. ${ }^{43} \mathrm{O}$ bevirimat (36) é um produto natural que provém da extração da planta chinesa Syzigium claviflorum (Figura 18). Atualmente encontra-se em fase clínica $\mathrm{II}^{44}$ com previsão de lançamento no mercado no final de 2008.

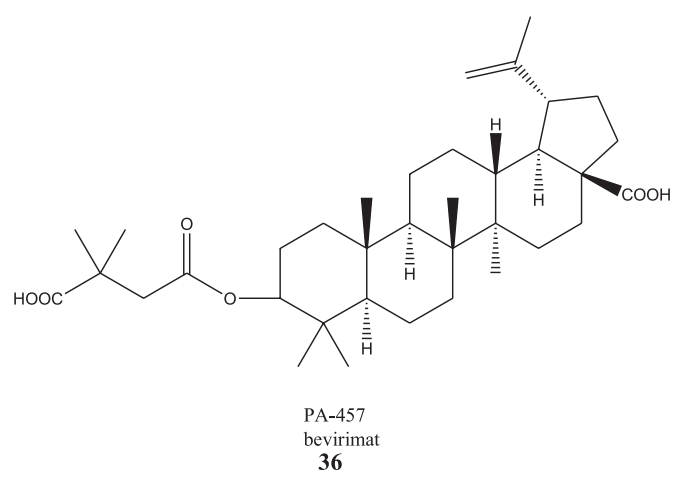

Figura 18. Estrutura do PA-457 (36), inibidor de maturação

\section{OUTROS ALVOS TERAPÊUTICOS}

Outros alvos terapêuticos estão em estudo, como os inibidores da transcrição, inibidores da Ribonucleose H (RNAse H) do HIV e moléculas que inativam a proteína nucleocapsídica (Ncp7). Entretanto, estão em fase clínica inicial, pré-clínica ou tiveram seus estudos suspensos. ${ }^{9,45}$

\section{CONCLUSÃO}

Nos últimos anos, houve um considerável progresso na quimioterapia para o tratamento da AIDS. Além dos já conhecidos inibidores nucleosídeos da transcriptase reversa, inibidores não-nucleosídeos da transcriptase reversa, da protease e da fusão, duas novas classes de inibidores estão disponíveis para o tratamento da infecção pelo HIV, os inibidores da integrase (raltegravir) e os antagonistas do co-receptor CCR5 (maraviroc). A Tabela 1 mostra os fármacos aprovados desde 2005.

Apesar desses avanços, a eficácia do tratamento da AIDS é limitada

Tabela 1. Fármacos aprovados pelo FDA no combate ao HIV

\begin{tabular}{lcc}
\hline Fármaco & Alvo terapêutico & Ano de lançamento \\
\hline tipranavir & Inibidor protease & 2005 \\
darunavir & Inibidor protease & 2006 \\
raltegravir & Inibidor integrase & 2007 \\
maraviroc & Antagonista do co-receptor & 2007 \\
& $\quad$ CCR5 & \\
etravirine & Inibidor não-nucleosídeo & 2008 \\
rilpivirine & da transcriptase reversa & \\
bevirimat & Inibidor não-nucleosídeo & $2008^{\mathrm{a}}$ \\
\hline
\end{tabular}

a - Previsão de lançamento 
pelo surgimento de HIV-1 resistentes aos medicamentos disponíveis, a toxidez dos mesmos e uma baixa resposta terapêutica de alguns indivíduos. Como consequiência, a busca de novos compostos inibidores para estes alvos conhecidos, bem como a busca de novos alvos terapêuticos, continua sendo um desafio que precisa ser alcançado.

\section{AGRADECIMENTOS}

À Farmanguinhos pelo apoio financeiro e ao CNPq pela bolsa de desenvolvimento tecnológico e industrial (W. T. Vellasco Jr.).

\section{REFERÊNCIAS}

1. Barre-Sinoussi, F.; Chermann, J. C.; Rey, F.; Nugeyre, M. T.; Chamaret, S.; Gruest, J.; Dauguet, C.; Axler-Blin, C.; Vezinet-Brun, F.; Rouzioux, C.; Rozenbaum, W.; Montagnier, L.; Science 1983, 220, 868.

2. Vaishnav, Y. N.; Wong-Stall, F.; Annu. Rev. Biochem. 1991, 60, 577.

3. Cooley; L. A.; Lewin, S. R.; J. Clin. Virol. 2003, 26, 121.

4. de Souza, M. V. N.; Rev. Bras. Farm. 2005, 86, 112.

5. Price, D. A.; Gayton, S.; Selby, M. D.; Ahman, J.; Haycock-Lewandowski, S.; Stammen, B. L.; Warren, A.; Tetrahedron Lett. 2005, 46, 5005.

6. Tagat, J. R.; McCombie, S. W.; Nazareno, D.; Labroli, M. A.; Xiao, Y.; Steensma, R. W.; Strizki, J. M.; Baroudy, B. M.; Cox, K.; Lachowicz, J.; Varty, G.; Watkins, R.; J. Med. Chem. 2004, 47, 2405.

7. McIntyre, J. A.; Castaner, J.; Drug Future 2004, 29, 677.

8. Esté, J. A.; Telenti, A.; The Lancet 2007, 370, 81.

9. De Clercq, E.; J. Med. Chem. 2005, 48, 1297.

10. Schinazi, R. F.; McMillan, A.; Cannon, D.; Mathis, R.; Lloyd, R. M.; Peck, A.; Sommadossi, J. P.; St. Clair, M.; Wilson, J.; Furman, P. A.; Painter, G.; Choi, W.-B.; Liotta, D. C.; Antimicrob. Agents Chemother. 1992, 36, 2423.

11. Mansour, T. S.; Jin, H.; Wang, W.; Hooker, E. U.; Ashman, C.; Cammack, N.; Salomon, H.; Belmonte, A. R.; Wainberg, M. A.; J. Med. Chem. 1995, 38, 1 .

12. Otto, M. J.; Curr. Opin. Pharmacol. 2004, 4, 431.

13. Shi, J.; McAtee, J. J.; Wirtz, S. S.; Tharnish, P.; Juodawlkis, A.; Liotta, D. C.; Schinazi, R. F.; J. Med. Chem. 1999, 42, 859.

14. Schinazi, R. F.; Mellors, J.; Bazmi, B.; Diamond, S.; Garber, S.; Gallagher, K.; Geleziunas, R.; Klabe, R.; Pierce,M.; Rayner, M.; Wu, J.-T.; Zhang, H.; Hammond, J.; Bacheler, L.; Manion, D. J.; Otto, M. J.; Stuyver, L.; Trainor, G.; Liotta, D. C.; Erickson-Viitanen, S.; Antimicrob. Agents Chemother. 2002, 46, 1394.

15. Gu, Z.; Wainberg, M. A.; Nguyen-Ba, N.; L'Heureux, L.; Muys, J.-M.; Bowlin, T. Y.; Rando, R. F.; Antimicrob. Agents Chemother. 1999, 43, 2376.

16. Siddiqui, M. A.; Brown, W. L.; Nguyen-Ba, N.; Dixit, D. M.; Mansour, T. S.; Hooker, E.; Viner, K. C.; Cameron, J. M.; Bioorg. Med. Chem. Lett. 1993, 3, 1543.

17. Starrett Jr., J. E.; Tortolani, D. R.; Russell, J.; Hitchcock, M. J. M.; Whiterock, V.; Martin, J. C.; Mansuri, M. M.; J. Med. Chem. 1994, 37, 1857.

18. Hadziyannis, S. J.; Tassapoulos, N. C.; Heathcote, E. J.; Chang, T.-T.; Kitis, G.; Rizzeto, M.; Marcellin, P.; Lim, S. G.; Goodman, Z.; Wulfsohn, M. S.; Xiong, S.; Fry, J.; Brosgart, C. L.; New Engl. J. Med. 2003, 348, 800; Marcellin, P.; Chang, T.-T.; Lim, S. G.; Tong, M. J.; Silvert, W.; Shiffman, M. L.; Jeffers, L.; Goodman, Z.; Wulfsohn, M. S.; Xiong, S.; Fry, J.; Brosgart, C. L.; New Engl. J. Med. 2003, 348, 808.

19. Shaw, J.-P.; Sueoka, C. M.; Oliyai, R.; Lee, W. A.; Arimilli, M. N.; Kim, C. U.; Cundy, K. C.; Pharm. Res.1997, 14, 1824.

20. De Clercq, E.; Holy, A.; Nature 2005, 4, 928.

21. Shen, L.; Shen, J.; Luo, X.; Cheng, F.; Xu, Y.; Chen, K.; Arnold, E.; Ding, J.; Jiang, H.; Biophys. J. 2003, 84, 3547.

22. De Clercq, E.; Chem. Biodiversity 2004, 1, 44.
23. Das, K.; Lewi, P.J.; Hughes, S.H.; Arnold, E.; Prog. Biophys. Mol. Bio. 2005, 88, 209.

24. Van Herrewege, K.; Michiels, J.; Van Roey, J.; Fransen, K.; Kestens, L.; Balzarini, J.; Lewi, P.; Vanham, G.; Janssen, P.; Antimicrob. Agents Chemother. 2004, 48, 337.

25. Ludovici, D. W.; De Corte, B. L.; Kukla, M. J.; Ye, H.; Ho, C. Y.; Lichtenstein, M. A.; Kavash, R. W.; Andries, K.; Béthune, M.-P.; Azijn, H.; Pauwels, R.; Lewi, P. J.; Heeres, J.; Koymans, L. M. H.; Jonge, M. R.; Van Aken, K. J. A.; Daeyaert, F. F. D.; Das, K.; Arnold, E.; Janssen, P. J.; Bioorg. Med. Chem. Lett. 2001, 11, 2235.

26. Guillemont, J.; Pasquier, E.; Palandjian, P.; Vernier, D.; Gaurrand, S.; Lewi, P. J.; Heeres, J.; Jonge, M. R.; Koymans, L. M. H.; Daeyaert, F. F. D.; Vinkers, M. H.; Arnold, E.; Das, K.; Pauwels, R.; Andries, K.; Béthune, M.-P.; Bettens, E.; Hertogs, K.; Wigerinck, P.; Timmerman, P.; Janssen, P. J.; J. Med. Chem. 2005, 48, 2072.

27. Cai, S.; Dimitroff, M.; McKennon, T.; Reider, M.; Robarge, L.; Ryckman, D.; Shang, X.; Therrien, J.; Org. Process Res. Dev. 2004, 8, 353.

28. Brik, A.; Wong, C.-H.; Org. Biomol. Chem. 2003, 1, 5.

29. Dorsey B. D.; Vacca, J. P. Em Protease Inhibitors in AIDS Therapy; Ogden, R. C.; Flexner, C. W., eds.; Marcel Dekker Inc.: New York, 2001, cap. 4.

30. Ghosh, A. K.; Bilcer, G.; Schiltz, G.; Synthesis 2001, 2203.

31. Turner, S. R.; Strohbach, J. W.; Tommasi, R. A.; Aristoff, P. A.; Jonhson, P. D.; Skulnick, H. I.; Dolak, L. A.; Seest, E. P.; Tomich, P. K.; Bohanon, M. J.; Horng, M. M.; Lynn, J. C.; Chong, K. T.; Hinshaw, R. R.; Watenpaugh, K. D.; Janakiraman, M. N.; Thaisrivongs, S.; J. Med. Chem. 1998, 41, 3467.

32. Rusconi, S.; Catamacio, S. La S.; Citterio, P.; Kurtagic, S.; Violin, M.; Balotta, C.; Moroni, M.; Galli, M.; d'Arminio-Monforte, A.; Antimicrob. Agents Chemother. 2000, 44, 1328.

33. Ghosh, A. K.; Kincaid, J. F.; Cho, W.; Walters, D. E.; Krishnan, K.; Hussain, K. A.; Koo, Y.; Cho, H.; Rudall, C.; Holland, L.; Buthod, J.; Bioorg. Med. Chem. Lett. 1998, 8, 687.

34. Surleraux, D. L. N. G.; de Kock, H. A.; Verschueren, W. G.; Pille, G. M. E.; Maes, L. J. R.; Peeters, A.; Vendeville, S.; De Meyer, S.; Azijn, H.; Pauwels, R.; de Bethune, M.-P.; King, N. M.; Prabu-Jeyabalan, M.; Schiffer, C. A.; Wigerinck, P. B. T. P.; J. Med. Chem. 2005, 48, 1965.

35. Kovalevsky, A. Y.; Liu, F.; Leshchenko, S.; Ghosh, A. K.; Louis, J. M.; Harrison, R. W.; Weber, I. T. J. Mol. Biol. 2006, 363, 161.

36. Hornak, V.; Simmerling, C.; Drug Discov. Today 2007, 12, 132.

37. Hanlon, M. H.; Porter, D. J. T.; Furfine, E. S.; Spaltenstein, A.; Carter, H. L.; Danger, D.; Shu, A. Y. L.; Kaldor, I. W.; Miller, J. F.; Samano, V. A.; Biochemistry 2004, 43, 14500.

38. de Mello, E. B.; Bruni, A. T.; Ferreira, M. M. C.; Quim. Nova 2006, 29, 555.

39. Dubey, S.; Satyanarayana, Y. D.; Lavania, H.; Eur. J. Med. Chem. 2007, $42,1159$.

40. Daelemans, D.; Lu, R.; De Clercq, E. ; J. Virol. 2007, 8, 4381; Dayam, R.; Al-Mawsawi, L.; Neamati, N.; Drugs R. D. 2007, 8, 155.

41. http://www.thebody.com/content/treat/art43527.html, acessada em Outubro 2007.

42. Sato, M.; Motomura, T.; Aramaki, H.; Matsuda, T.; Yamashita, M.; Ito, Y.; Kawakami, H.; Matsuzaki, Y.; Watanabe, W.; Yamataka, K.; Ikeda, S.; Kodama, E.; Matsuoka, M.; Shinkai, H.; J. Med. Chem. 2006, 49, 1506.

43. Li, F.; Goila-Gaur, R.; Salzwedel, K.; Kilgore, N. R.; Reddick, M.; Matallana, C.; Castillo, A.; Zoumplis, D.; Martin, D. E.; Orenstein, J. M.; Allaway, G. P.; Freed, E. O.; Wild, C. T.; Proc. Natl. Acad. Sci. U.S.A. 2003, 100, 13555.

44. Smith, P. F.; Ogundele, A.; Forrest, A.; Wilton, J.; Salzwedel, K.; Doto, J.; Allaway, G. P.; Martin, D. E.; Antimicrob. Agents Chemother. 2007, $51,3574$.

45. de Souza, M. V. N.; Almeida, M. V.; Quim. Nova 2003, 26, 366. 